\title{
ISOLATION, CHARACTERIZATION, AND DOCKING STUDIES OF ISOLATED COMPOUNDS AS ANTIDIABETIC MOLECULES FROM CRESSA CRETICA
}

\author{
SANGEETA RANI ${ }^{1 *}$, KAVITA GAHLOT ${ }^{2}$, ARVIND KUMAR ${ }^{3}$
}

${ }^{1}$ Department of Pharmacognosy, S.D. College of Pharmacy and Vocational Studies, Muzaffarnagar, Uttar Pradesh, India. ${ }^{2}$ Departments of Pharmacognosy, IFTM University, Moradabad, Uttar Pradesh, India. ${ }^{3}$ Department of Pharmaceutical Chemistry and Drug Design, S.D. College of Pharmacy and Vocational Studies, Muzaffarnagar, Uttar Pradesh, India. Email: rsangeetapharma@gmail.com

Received: 10 January 2019, Revised and Accepted: 10 February 2020

ABSTRACT

Objective: The purpose of this study was to investigate the diabetic effect of phytocompounds isolated from Cressa cretica Linn. using spectroscopic analysis and molecular docking studies.

Methods: Coarse powder of the whole plant of $C$. cretica was extracted with methanol, extracted part was subjected to silica column isolation, and two compounds: 2-Isopropyl-4-(1-methyl-dodeca-2,4-dienyloxy)-benzene-1,3,5-triol (Compound CN-01) and 11-Methyl-dodeca-2,4,6,8,10-pentenoic acid 2,3-dihydroxy-5-methyl-phenyl ester (Compound CN-02) were isolated in pure form. The three-dimensional structure of target protein was downloaded from PDB (www.rcsb.org) Protein Data Bank, Ligand file CN - 01 and CN - 02 were converted to MDL Molfile (V2000) format using ChemSketch 2017.2.1. These files could not be used directly in AutoDock 4.0 tools; thus, they were first converted to PDB files using an open babel tool.

Results: Compounds were revealed through spectroscopic analysis and screened using AutoDock 4.0 tools. Docking study recommended that CN - 01 and $\mathrm{CN}-02$ an existing phytochemical from the plant of $C$. cretica had the highest fitness docking score and hence could be a potent antidiabetic drug.

Conclusion: In this investigation, we docked the receptor (glycogen phosphorylase protein) holds a promising lead target formation against diabetes based on molecular docking analysis (minimum hydrogen bond length and maximum docked score). Thus, these compounds can be effectively used as drugs for treating diabetes which is predicted on the basis of docking scores.

Keywords: Cressa cretica, Spectroscopic analysis, Phytocompounds, Glycogen phosphorylase protein, Docking, Diabetes.

(C) 2020 The Authors. Published by Innovare Academic Sciences Pvt Ltd. This is an open access article under the CC BY license (http://creativecommons. org/licenses/by/4. 0/) DOI: http://dx.doi.org/10.22159/ajpcr.2020.v13i4.36836

\section{INTRODUCTION}

Diabetes mellitus is a heterogeneous metabolic disorder characterized by the common feature of chronic hyperglycemia with disturbance of carbohydrate, fat, and protein metabolism [1-4] and by complications such as microvascular and macrovascular complications [5]. A worldwide survey has reported that diabetes mellitus affects nearly $10 \%$ of the population [6]. It has been predicted that the prevalence of diabetes in adults will increase from 135 million in 1995-350 million in 2030, as given by the International Diabetes Federation [7,8]. At present, available synthetic antidiabetic agents produce serious side effects such as hypoglycemic coma and hepatorenal disturbances. Patients are, therefore, using herbal medicines which have fewer side effects and have the potential to impart therapeutic effect in complicated disorders such as diabetes and its complication [9-12].

Plants are well known in traditional herbal medicine for their hypoglycemic activities and available literature indicates that there are more than 800 plant species showing hypoglycemic activity. There has been increasing demand for the use of plant products with antidiabetic activity due to low cost, easy availability, and lesser side effects. One such plant is Cressa cretica Linn. which has been used in Traditional System of Indian Medicine for treating diabetes. The plant commonly known as Rudravanti is an erect, small, and dwarf shrub [13], belonging to family Convolvulaceae [14,15], and used in diabetes and many other disease [16]. It is reported to be antibilious, antitubercular, and cough medicine. The plant is used for alternative anthelmintic, stomachic, tonic, and aphrodisiac purposes, enriches the blood, and is useful in constipation, leprosy, asthma, and urinary discharges. The plant is traditionally used in Bahrain as expectorant and antibilious agent [17].
The aim of this research is to investigate the antidiabetic constituents present in the entire plant of $C$. cretica using spectroscopic analysis and molecular docking prediction. In silico docking procedures have also been carried out to examine the interactions of the plant components with diabetic targets. The widespread uses of $C$. cretica in traditional medicine have resulted in significant qualitative analysis of the plant and its active principles.

\section{METHODS}

Plant material

The plant of $C$. cretica L. Convolvulaceae was collected for the research work from Andhra Pradesh. The plant was identified and authenticated by Dr. K. Madhava Chetty, plant taxonomist (IAAT, 357), SVU, Andhra Pradesh, India.

\section{Extraction and isolation}

The collected plant material of $C$. cretica was washed thoroughly in tap water, dried under the shade, pulverized, and sieved. Coarsely powdered drug was subjected to successive extraction in a Soxhlet apparatus with solvents of increasing polarity, namely, petroleum ether, chloroform, ethyl acetate, methanol, and water. The individual extract was filtered, concentrated to a small volume in a rotary vacuum evaporator followed by drying in china dishes on a hot water bath.

Removal of the solvent in a vacuum gave the $\mathrm{MeOH}$ extract, which was partitioned in water and extracted with petroleum ether, chloroform, ethyl acetate, and n-BuOH. The n-BuOH layer was concentrated and the residue was chromatographed, eluted with water and $\mathrm{MeOH}$. The $\mathrm{MeOH}$ residue was fractionated by column chromatography on normal-phase silica gel, eluted with gradient PE/CHCl3 (6:4 and 1:1) 
afforded two fractions (Fr.1 and Fr.2). These compounds were isolated using a chromatographic column on the normal-phase silica gel column [18- 22].

\section{In silico molecular docking studies}

The molecular docking study provides a significant view of the bindings and conformations of ligand-enzymes [23]. To explore the activities of newly synthesized compounds and binding interactions of ligand and glucose phosphorylase $B$, ligands were docked into the site of glucose phosphorylase B (PDB code: $1 \mathrm{H} 5 \mathrm{U}$ ).

\section{Preparation of ligand structures}

Ligand file CN - 01 and CN - 02 were converted to MDL Molfile (V2000) format using ChemSketch 2017.2.1. These files could not be used directly in AutoDock 4.0; thus, they were first converted to PDB files using open babel tool [24].

\section{Preparation of protein structure}

The three-dimensional structure of the target protein was downloaded from PDB (www.rcsb.org) Protein Data Bank. Optimization of protein was done by removing HETATOM using SPDB-Swiss PDB viewer.

\section{Grid formation}

The grid was centered in the active site region, which involves all functional amino acid residues. A grid box is set with a dimension of $60 \times 60 \times 60$, with the default grid points spacing $0.37 \AA$. The dimension will change depending on the ligand size. Lamarckian genetic algorithm (LGA) [25] was used for the flexible docking calculations. The LGA parameters such as population size (ga_pop_size), energy evaluations (ga_num_generation), mutation rate, crossover rate, and step size were set to $150,2,500,000$, $27,000,0.02,0.8$, and $0.2 \AA$, respectively. The LGA runs were set at ten runs. All obtained conformations of enzymes and compound complexes analyzed the interactions and binding energy of the docked structure using USF Chimera, Molegro Molecular Viewer (MMV 2008.1.2.0), Ligplot+v.2.1.

\section{Molecular docking}

Docking study was performed on EXHZ version 1.4 and Auto Dock 4.0 on Fedora Linux WS 3.0. To identify potential antidiabetic lead compounds among all synthesized compounds, the 2D structure construction, energy minimization, and geometry optimization of the penetration enhancer were carried out using ACD/ChemSketch 2017.2.1 and Chem3D Pro 7.0 (Cambridge Soft Corporation, 100 Cambridge Park Drive, Cambridge MA, 02140 USA) on an Intel(R) Core

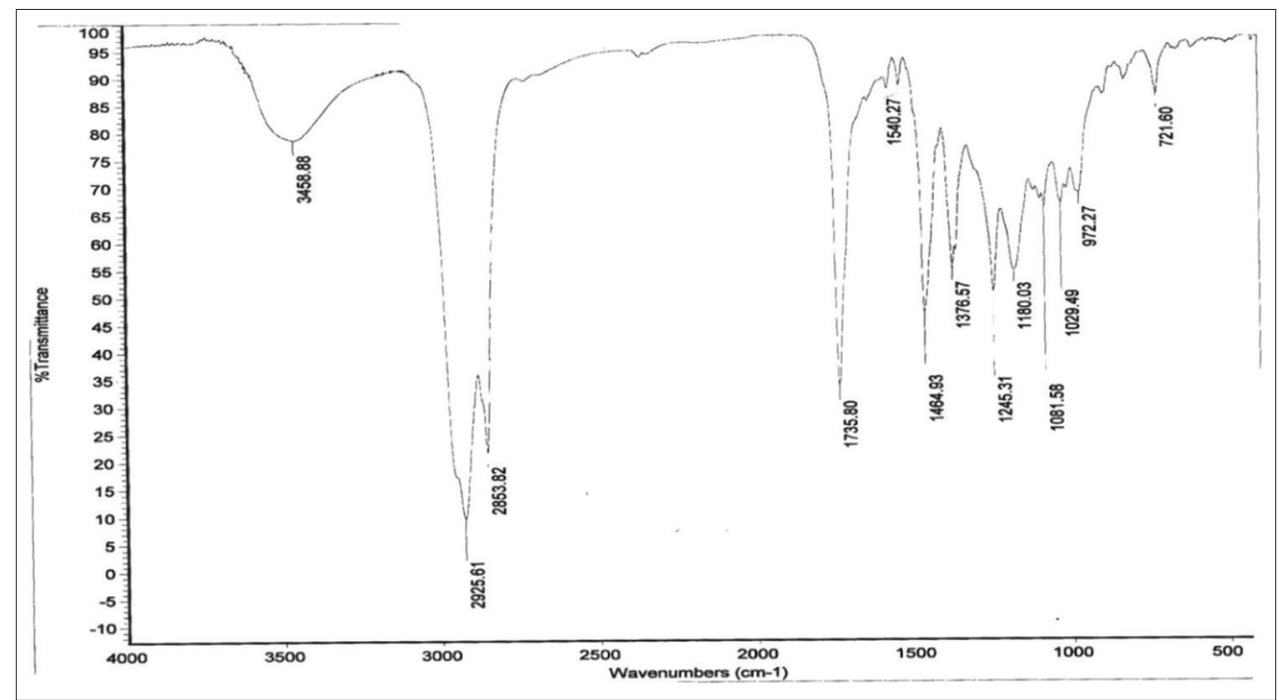

Fig. 1: Infrared spectrum of $\mathrm{CN}-01$

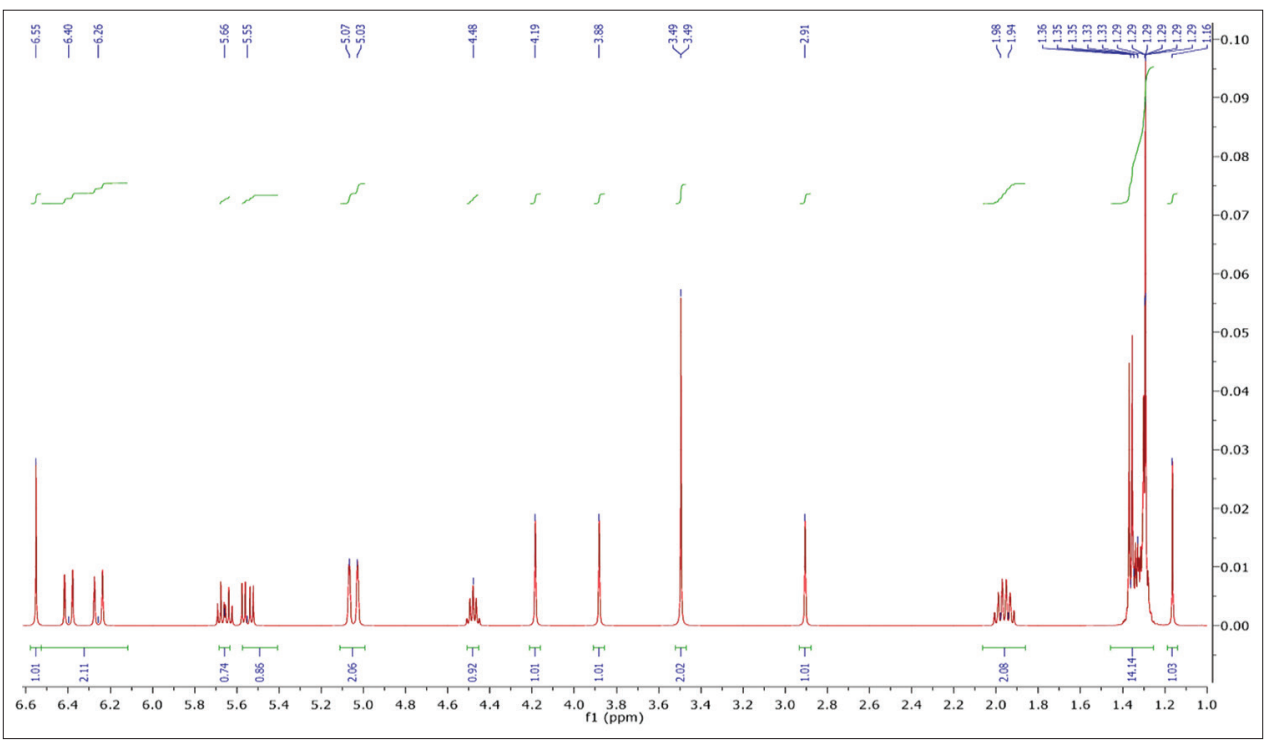

Fig. 2: Proton nuclear magnetic resonance spectrum of $\mathrm{CN}-01$ 
(TM)2 Duo Central Processing Unit T $6670 @ 2.20 \mathrm{GHz}$ and $4.00 \mathrm{~GB}$ of RAM, running the Windows 7 Home Basic, 64-bit compatible operating system. The energy minimization was carried out to a minimum RMS Gradient of 0.100 , with a step interval of 2.0 Fs and frame interval of 10 .

LGA is used to create a set of possible conformations. LGA is used as a global optimizer and energy minimization as a local search method. The minimum binding affinity was calculated for compounds $(\mathrm{CN}-01$ and $\mathrm{CN}-02$ ) with glycogen phosphorylase B using molecular docking tool AutoDock 4.0. The corresponding ligands are docked to the active site of each protein using AutoDock 4.0 to find best-docked conformation for the protein structures. The docking score, hydrogen-bonded residue, and hydrophobic interaction such as alkyl and pi alkyl, Van der Waals interaction were recorded.

\section{RESULTS AND DISCUSSION}

Compound CN-01(2-isopropyl-4-[1-methyl-dodeca-2,4-dienyloxy]benzene-1,3,5-triol)

Elution of the column with petroleum ether: chloroform (6:4) afforded white crystalline powder of $\mathrm{CN}-01$, recrystallized from methanol, $80 \mathrm{mg}$.
Melting point: $210-215^{\circ} \mathrm{C}$. Infrared (IR) $\left(\mathrm{KBr}, \mathrm{v} \max / \mathrm{cm}^{-1}\right): 3458.88$

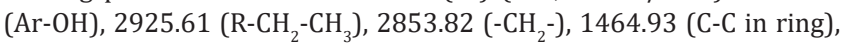
$1376.57\left(-\mathrm{CH}_{3}\right), 1245.31$ (Ar-O-R). Proton nuclear magnetic resonance $\left({ }^{1} \mathrm{H} \mathrm{NMR}\right.$ ) ( $400 \mathrm{MHz}, \mathrm{CDCl}_{3}, \delta$ in ppm): 1.16 (s, $1 \mathrm{H}$ of OH at C9), 1.29 (m, $3 \mathrm{H}$ of $\mathrm{C} 21, \mathrm{C} 22$ and $\mathrm{C} 23$ ), 1.33 (m, 1H of C20), 1.35 (m, 1H of C24), 1.36 (m, 1H of C26), 1.94, 1.98 (d, 2H of C19), 2.91 (s, 1H of C6), 3.49 (m, 2H of $\mathrm{OH}$ at $\mathrm{C} 2$ and C7), 3.88 (s, $1 \mathrm{H}$ of C6), 4.19 (s, 1H of C6), 4.48 (s, $1 \mathrm{H}$ of C14), 5.03, 5.07 (d, 2H of C5), 5.55 (s, 1H of C15), 5.66 (s, 1H of C18), 6.26 (d, 1H of C17), 6.40 (d, 1H of C16), 6.55 (s, 1H of C8). Carbon-13 nuclear magnetic resonance $\left({ }^{13} \mathrm{C} \mathrm{NMR}\right)\left(\mathrm{CDCl}_{3}, 100 \mathrm{MHz}, \delta\right.$ in ppm): 14.02 (s, C25), 19.38 (s, C26), 22.18 (s, C6), 22.94 (s, C24), 28.73 (s, C21), 29.6 (d, C22), 29.25 (d, C20), 31.29 (s, C19), 31.65 (s, C23), 76.00 (s, C14), 92.81 (s, C8), 103.04 (s, C3), 122.69 (s, C5), 127.14 (s, C16), 129.98 (d, C17), 130.08 (d, C1), 132.58 (s, C15), 135.84 (s, C18), 137.66 (s, C4), 150.81 (s, C2), 152.24 (s, C9), 155.79, (s, C7). MS (m/z, \%): (360.25, M, 7.7\%).

IR spectrum (Fig. 1) of compound CN 01 showed characteristic absorption bands for Ar- $\mathrm{OH}$ at $3458.88 \mathrm{~cm}^{-1}$, carbon chain $\mathrm{R}-\mathrm{CH}_{2}-\mathrm{CH}_{3}$ at $2925.61 \mathrm{~cm}^{-1},-\mathrm{CH}_{2}-$ at $2853.82, \mathrm{C}-\mathrm{C}$ in the ring at 1464.93 , methyl group $-\mathrm{CH}_{3}$ at 13.76 .57 and ester Ar-O-R at $1245.31 \mathrm{~cm}^{-1}$. The ${ }^{1} \mathrm{H}$ NMR spectrum (Fig. 2) of CN 01 showed a one-proton singlet at $\delta 1.16$

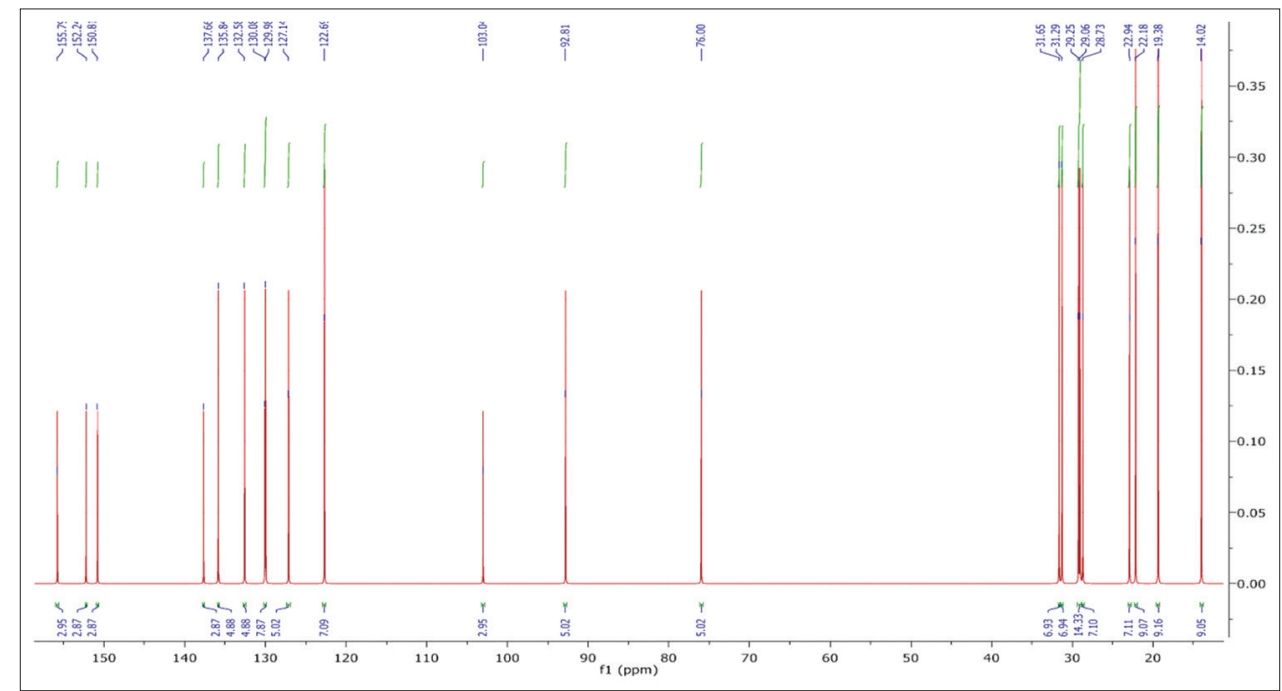

Fig. 3: Carbon-13 nuclear magnetic resonance spectrum of $\mathrm{CN}-01$

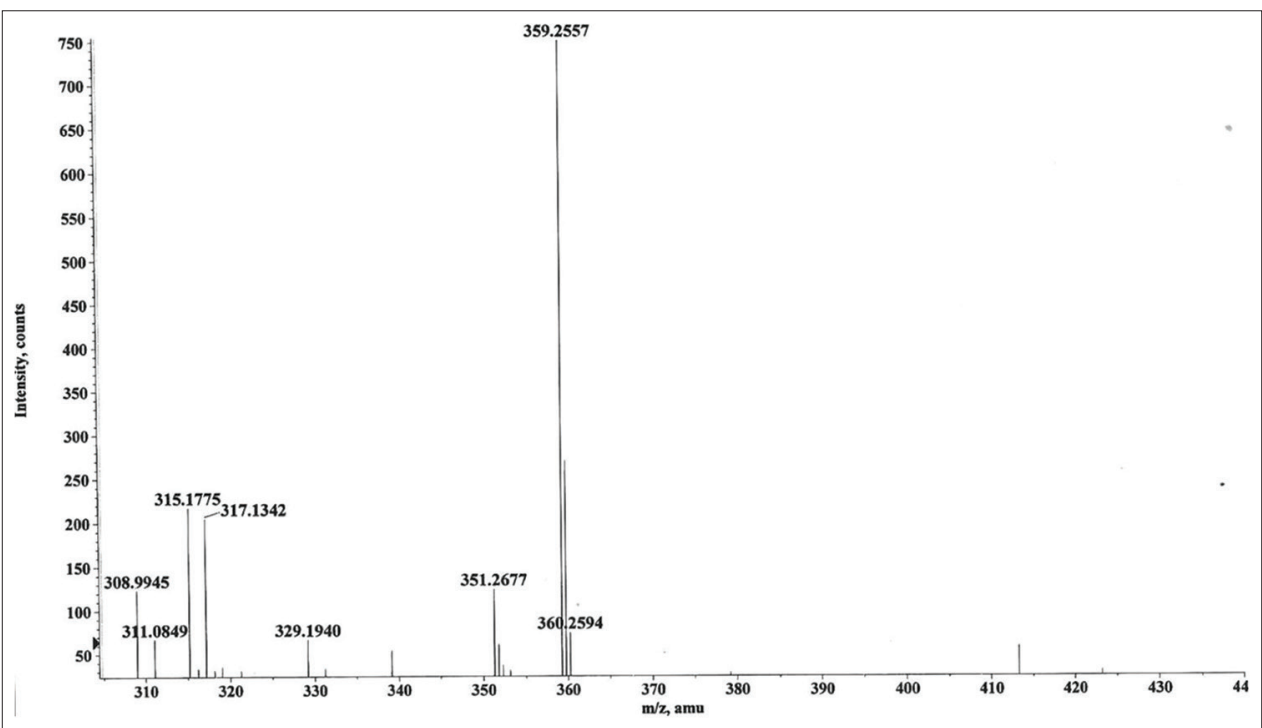

Fig. 4: Mass spectrum of $\mathrm{CN}-01$ 


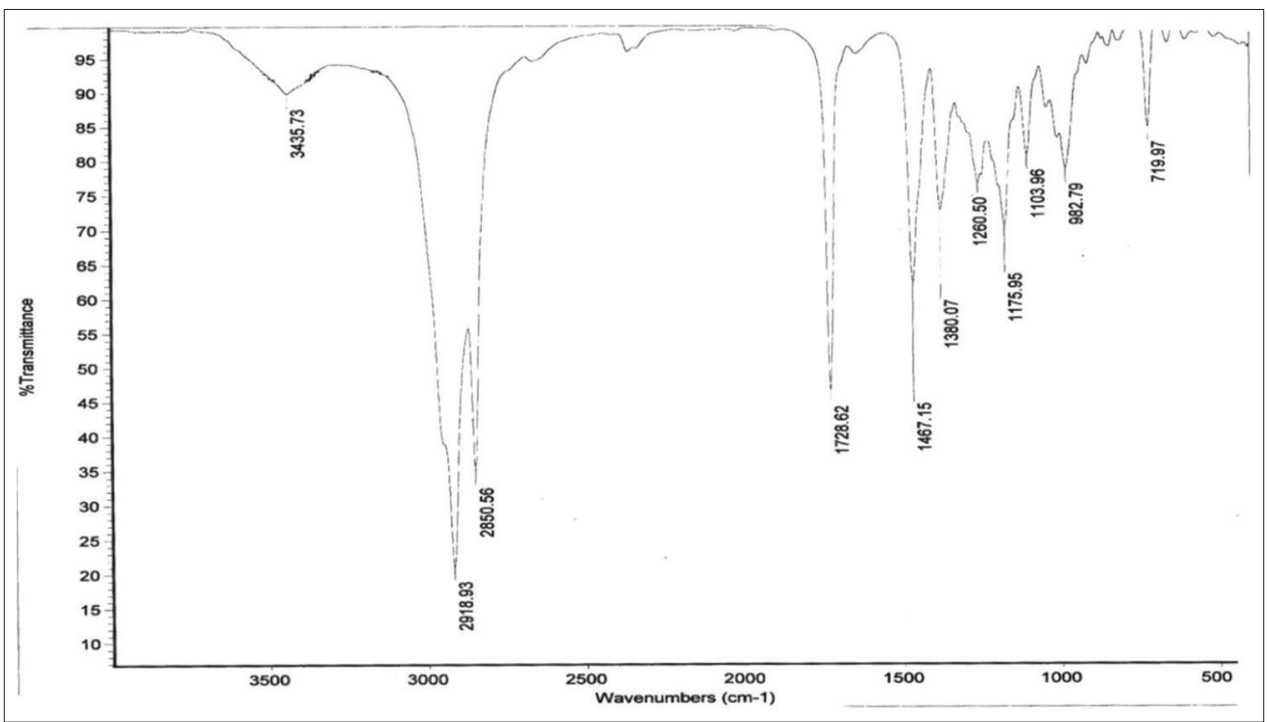

Fig. 5: Infrared spectrum of $\mathrm{CN}-\mathrm{O2}$

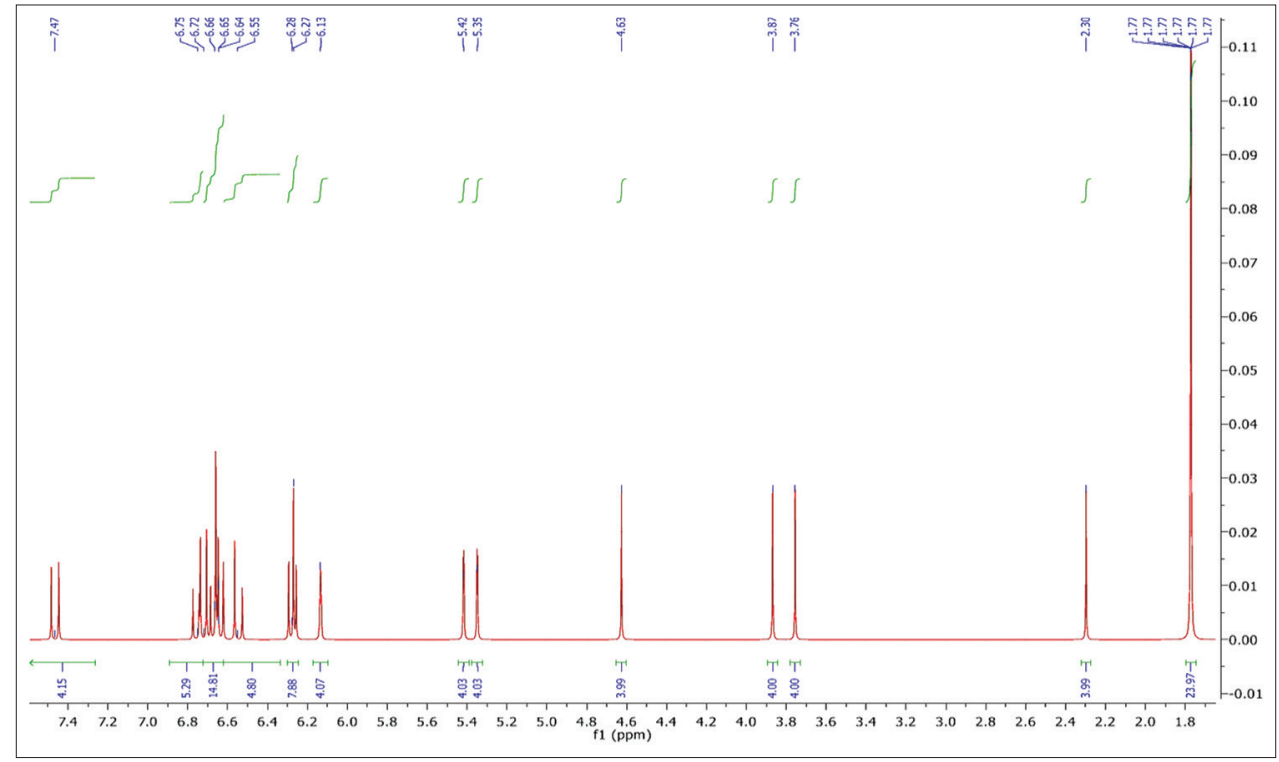

Fig. 6: Proton nuclear magnetic resonance spectrum of $\mathrm{CN}-02$

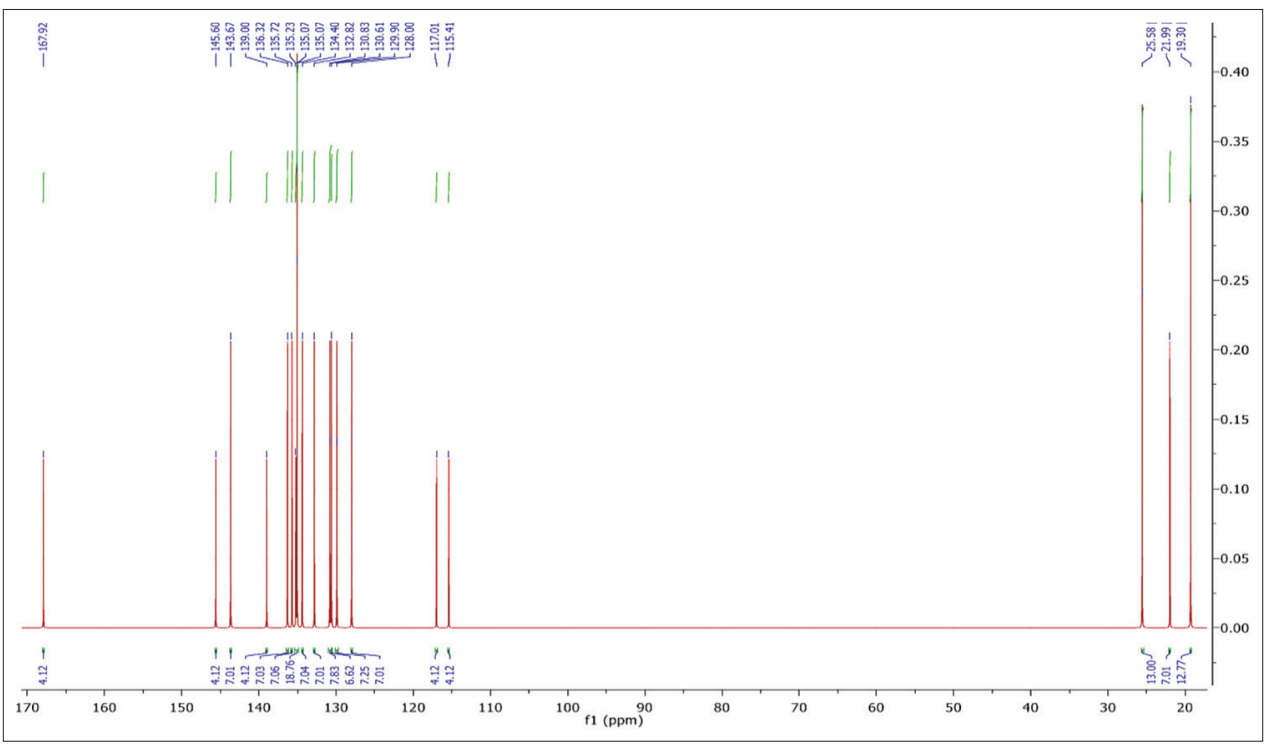

Fig. 7: Carbon-13 nuclear magnetic resonance spectrum of $\mathrm{CN}-02$ 


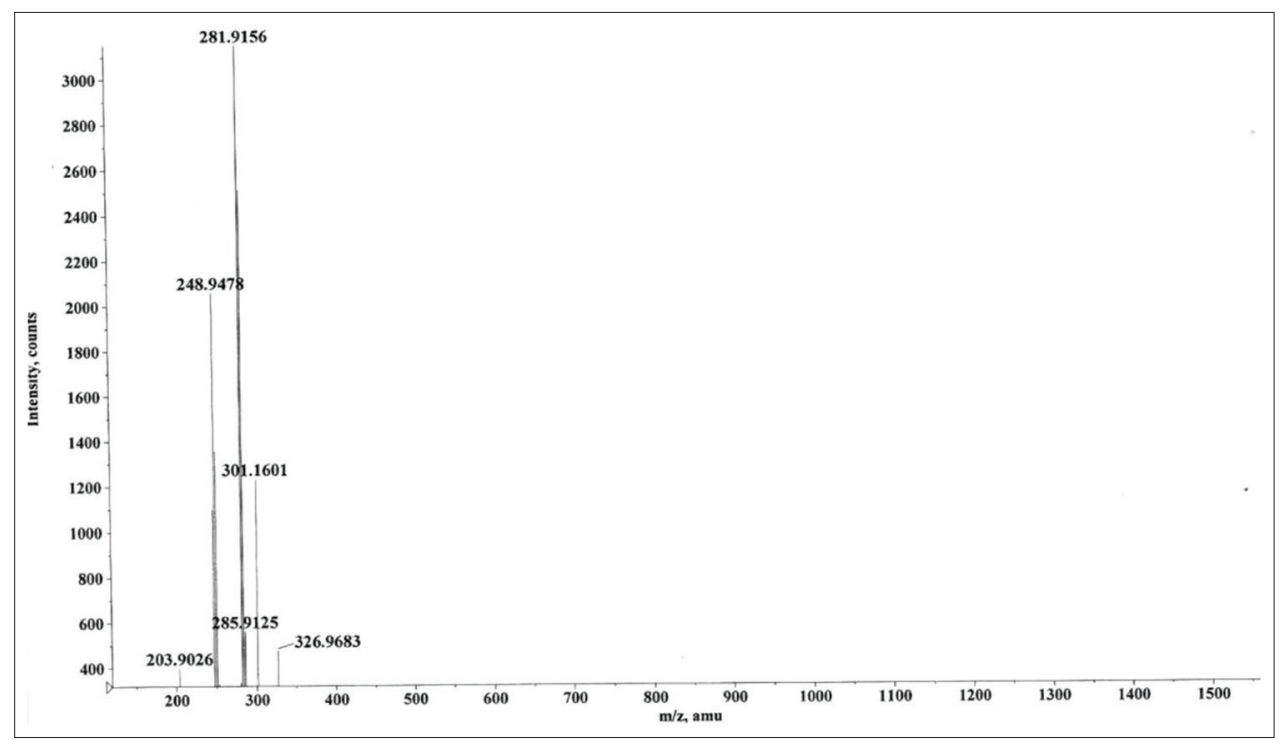

Fig. 8: Mass spectrum of $\mathrm{CN}-02$<smiles>C=CCCC/C=C/C=C/C=C/C=C/C(C)Oc1c(O)cc(O)c(C(=C)C)c1O</smiles>

Fig. 9: Structure of $\mathrm{CN}-01$<smiles>CC(C)=C/C=C/C=C/C=C/C=C/C(=O)Oc1cc(C)cc(O)c1O</smiles>

Fig. 10: Structure of CN-02

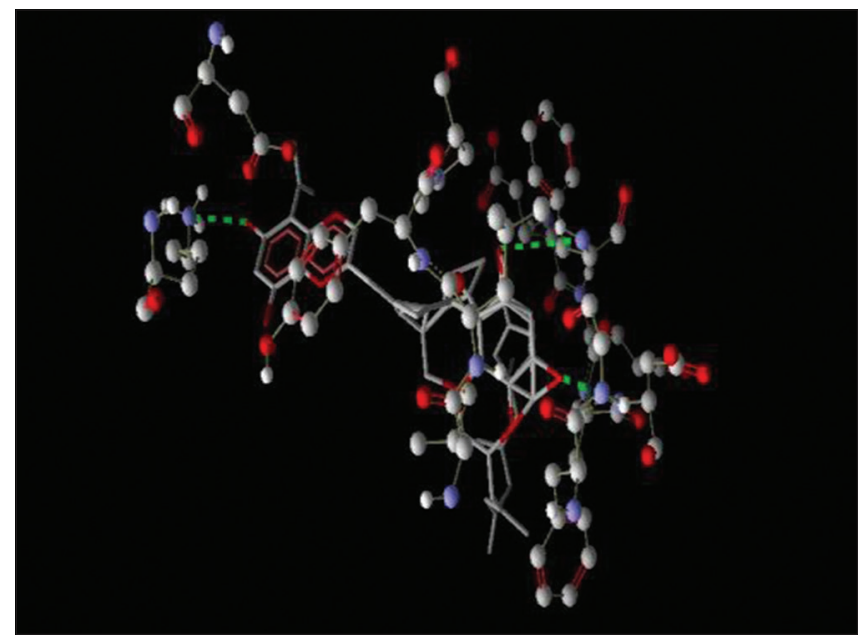

Fig. 11: Hydrogen bonding interaction of compound $\mathrm{CN}-01$ with 1h5u assigned to proton of $-\mathrm{OH}$ at $\mathrm{C} 9$. A three-proton multiplet at 1.29 was ascribed to protons of $\mathrm{C} 21,22$, and 23 . One multiplet at $\delta 1.33$ of C20, 1.35 at C24, 1.36 at C26, doublet at 1.94 and 1.98 for C19 with 2 protons. One singlet found at 2.91 of $\mathrm{C} 6$ for 1 proton. A multiplet for two protons of $-\mathrm{OH}$ at $\mathrm{C} 2$ and $\mathrm{C} 7$ were found at 3.49. Singlet for $\mathrm{C} 6$ was observed at 3.88. One proton was found that was at 4.19 as a singlet of C6. For C14, a singlet has been found at 4.48 for one proton. A doublet has been found at 5.03 and 5.07 for 2 protons at C5. AT 5.55 a single has been found for 1 proton against C15. 5.56 is correspondence to a singlet for one proton at $\mathrm{C} 18$, whereas 6.26 and 6.40 corresponds to a doublet for C17 and C16, respectively. A singlet has been found at 6.55 for one proton corresponds to $\mathrm{C} 8$. The ${ }^{13} \mathrm{C}$ NMR spectrum (Fig. 3) of compound $\mathrm{CN} 01$ showed signals for oxymethylene at $\delta 76.00$ of $\mathrm{C} 14$, methine carbons in the range of 137.66-122.69 attributed to C4, C5, and C15-18. Signals for the methyl group were observed in the range of 22.18-14.02 for C6, C25, and C26. Its mass spectrum (Fig. 4) exhibited a molecular ion peak at $\mathrm{m} / \mathrm{z} 360.25$, consistent with the molecular formula $\mathrm{C}_{22} \mathrm{H}_{32} \mathrm{O}_{4}$.

Compound $\mathrm{CN}-02$ (11-methyl-dodeca-2,4,6,8,10-pentenoic acid 2,3-dihydroxy-5-methyl-phenyl ester)

Elution of the column with petroleum ether: chloroform (1:1) afforded white crystalline powder of $\mathrm{CN}-02$, recrystallized from methanol, $86 \mathrm{mg}$.

Melting point $180-184^{\circ} \mathrm{C}$. IR $\left(\mathrm{KBr}, \mathrm{v} \max / \mathrm{cm}^{-1}\right)$ : $3435.73(\mathrm{Ar}-\mathrm{OH})$, 1467.15 (C-C in ring), $1380.07\left(-\mathrm{CH}_{3}\right), 1260.50$ (Ar-O-R), 1175.95 (R-COO-R'), 719.97 (R-CH=CH-R). ${ }^{1} \mathrm{H}$ NMR ( $400 \mathrm{MHz}, \mathrm{CDCl}_{3}, \delta$ in ppm): 1.77 (m, 6H of C23 and C24), 2.30, 3.76, 3.87 (s, 3H of C20), 4.63 (s, $1 \mathrm{H}$ of OH at C15), 5.35 (s, 1H of C17), 5.42 (s, 1H of C19), 6.13 (s, 1H of C10), 6.27 (d, 1H of OH at C16), 6.28 (d, 1H of C2), 6.55 (s, 1H of C9), $6.64(\mathrm{~m}$, $1 \mathrm{H}$ of C4), 6.65 (m, 1H of C6), 6.66 (m, 1H of C9), 6.72 (m, 1H of C7), 6.75 (s, $1 \mathrm{H}$ of $\mathrm{C} 5), 7.47$ (s, $1 \mathrm{H}$ of C3). ${ }^{13} \mathrm{C}$ NMR $\left(100 \mathrm{MHz}, \mathrm{CDCl}_{3}, \delta\right.$ in ppm): 19.30 (s, C23), 21.99 (s, C20), 25.58 (s, C24), 115.41 (s, C19), 117.01 (s, C17), 128.00 (s, C10), 129.90 (s, C2), 130.61 (s, C8), 130.83 (s, C18), 132.82 (s, C9), 134.40 (s, C4), 135.07 (m, C6), 135.23 (m, C15), 135.72 (s, C11), 136.32 (s, C5), 139.00 (s, C14), 143.67 (s, C3), 145.60 (s, C16), 167.92 (s, C1). MS (m/z, \%): (326.96, M, 5.8\%).

IR spectrum (Fig. 5) showed compound CN 02 characteristic absorption bands for Ar-OH at $3435.73 \mathrm{~cm}^{-1}$, C-C in ring at $1467.15 \mathrm{~cm}^{-1}$, methyl group $-\mathrm{CH}_{3}$ at $1380.07 \mathrm{~cm}^{-1}$, ether Ar-O-R at $1260.50 \mathrm{~cm}^{-1}$, aliphatic ester R-COO-R' at 1175.95, and alkene chain R-CH=CH-R at $719.97 \mathrm{~cm}^{-1}$. In ${ }^{1} \mathrm{H}$ NMR (Fig. 6) spectrum of CN 02, a six-proton multiplet at $\delta 1.77$ was ascribed to protons of $\mathrm{C} 23$, and 24. Three singlets at $\delta 2.30,3.76$, and 3.87 were ascribed to three-protons of C20. One-proton singlet at $\delta 4.63$ was assigned to proton of $-\mathrm{OH}$ at $\mathrm{C} 15$. One singlet at $\delta 5.35$ of $\mathrm{C} 17,5.42$ 
of $\mathrm{C} 19$, and 6.13 of $\mathrm{C} 10$ was assigned for 1 proton. A doublet has been found at $\delta 6.27$ for one proton of $-\mathrm{OH}$ at $\mathrm{C} 16$ and at $\delta 6.28$ for one proton at $\mathrm{C} 2$. One proton was found at 6.55 as a singlet of $\mathrm{C} 9$. One multiplet at $\delta 6.64$ of $\mathrm{C} 4,6.65$ of $\mathrm{C} 6,6.66$ of $\mathrm{C} 9$, and 6.72 of $\mathrm{C} 7$ was assigned for 1 proton. One singlet at $\delta 6.75$ of C5 and 7.47 of C 3 was assigned for 1 proton. ${ }^{13} \mathrm{C}$ NMR (Fig. 7) spectrum showed signals for ester carbon at $\delta$ 167.92 (C1), aromatic carbons between $\delta 145.60$ and 115.41 (C14-C19), methine carbons in the range of 143.67-128.0 attributed to C2-C11.
Signals for the methyl group were observed in the range of 25.58-19.30 for C20, C23, and C24. Its mass spectrum (Fig. 8) exhibited a molecular ion peak at m/z 326.96 consistent with the molecular formula $\mathrm{C}_{20} \mathrm{H}_{22} \mathrm{O}_{4}$.

Isolated compound obtained from fractions of $\mathrm{PE} / \mathrm{CHCl} 3(6: 4$ and 1:1) solvent system in the column and the presence of bioactive compounds was confirmed by thin-layer chromatography and melting point. The structure of isolated compound confirmed with the help of spectral studies

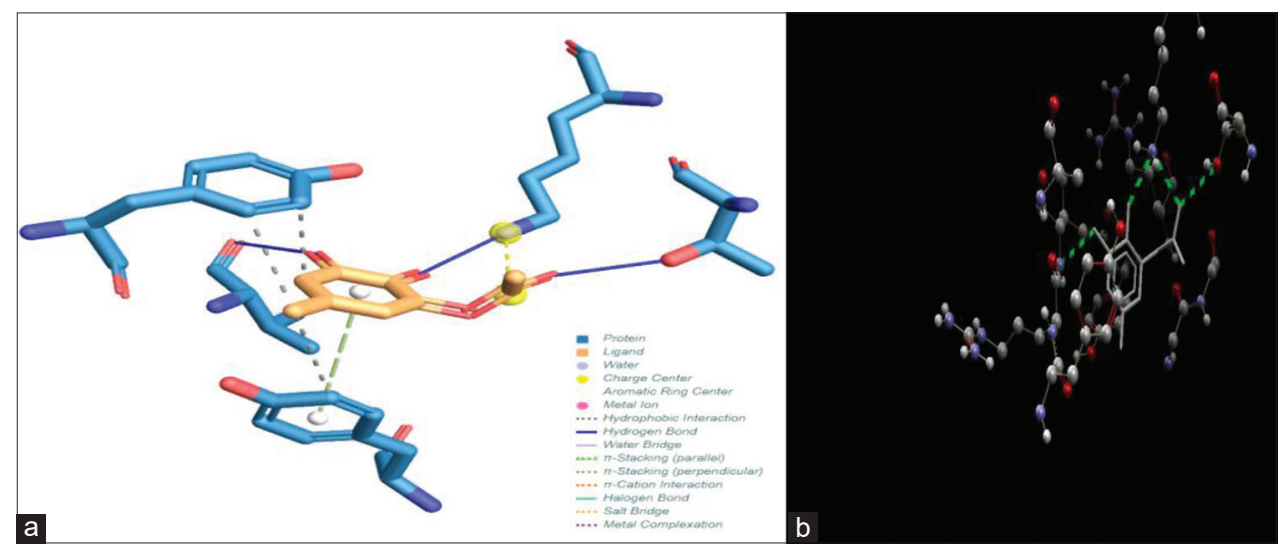

Fig. 12: (a) Hydrogen bonding interaction of compound $\mathrm{CN}-02$ with $1 \mathrm{~h} 5 \mathrm{u}$ in PLIP tool (b) hydrogen bonding interaction of compound CN - 02 with $1 \mathrm{~h} 5 \mathrm{u}$

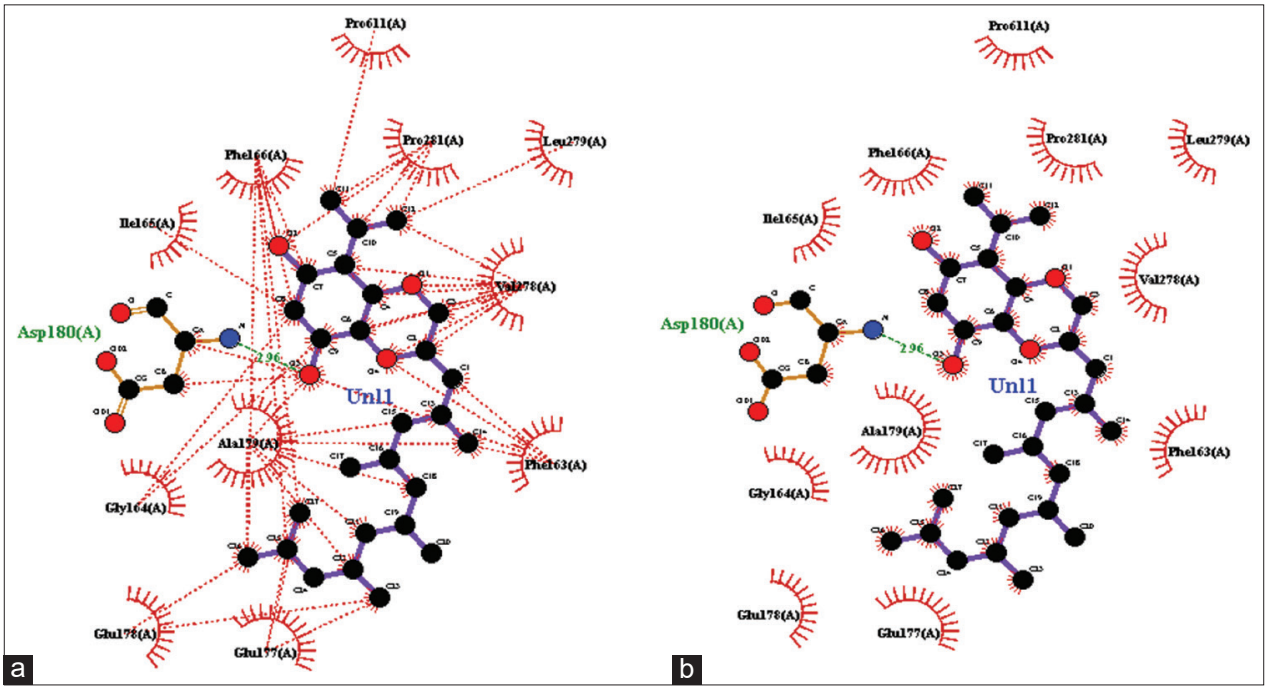

Fig. 13: (a) Hydrophilic interaction of CN - 01 with $1 \mathrm{~h} 5 \mathrm{u}$ in ligplot+tool (b) hydrogen bonding interaction of $\mathrm{CN}-01 \mathrm{with} 1 \mathrm{~h} 5 \mathrm{u}$ in ligplot+tool

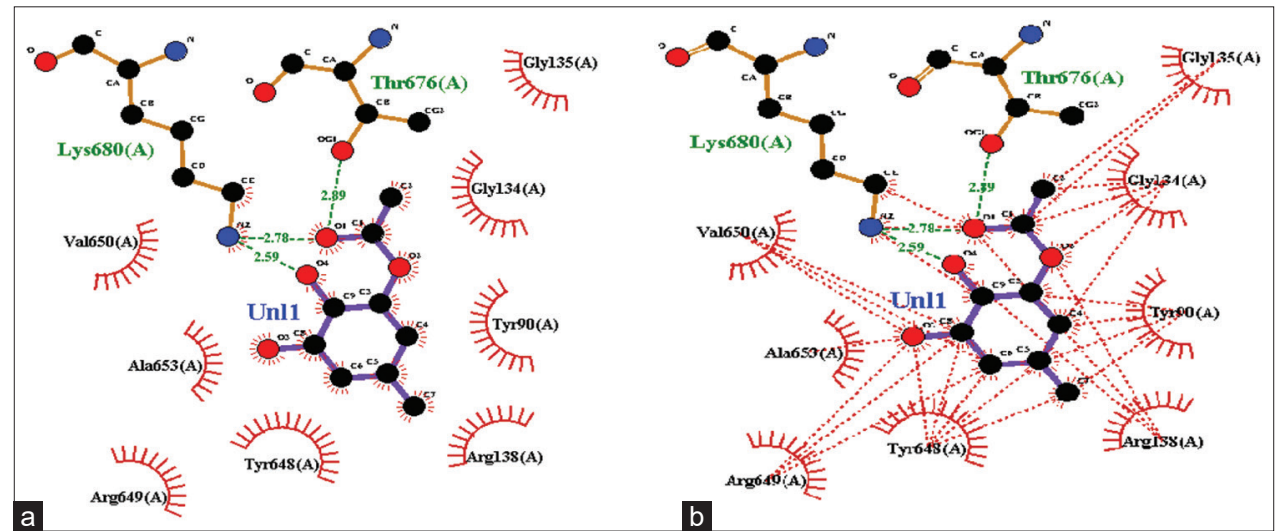

Fig. 14: (a) Hydrogen bonding interaction $\mathrm{CN}-02$ with $1 \mathrm{~h} 5 \mathrm{u}$ in ligplot+tool (b) hydrophilic interaction of $\mathrm{CN}-02 \mathrm{of}$ with $1 \mathrm{~h} 5 \mathrm{u}$ in ligplot+tool 


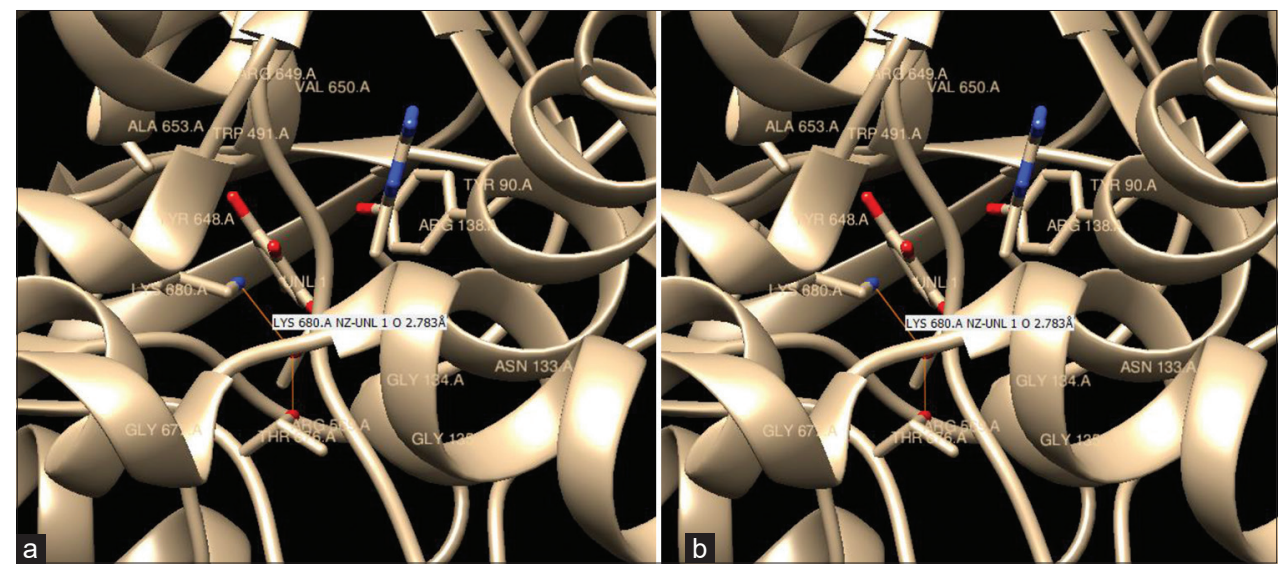

Fig. 15: (a) Hydrogen bonding CN - 02 with LYS 680_A (b) hydrogen bonding CN - 02 with THR 676.A

such as IR, ${ }^{1} \mathrm{H}$ NMR, ${ }^{13} \mathrm{C}$ NMR, and mass spectrometry. Interpretation data reveal that positive with $\mathrm{CN}-01$ (Fig. 9) and $\mathrm{CN}-02$ (Fig. 10).

\section{Docking study}

Glycogen phosphorylase is the main enzyme in muscle control and the metabolism of hepatic glycogen [26] and catalyzes the first step in intracellular degradation of glycogen to produce glucose- 1-phosphate [27]. The minimum binding capacity of CN - 01 (Fig. 11) and CN - 02 (Fig. 12) compounds with glycogen phosphorylase protein $(1 \mathrm{~h} 5 \mathrm{u})$ was calculated. Docking analysis showed that the compound $\mathrm{CN}-01$ had the binding affinity $(\Delta \mathrm{G}$, Binding energy=-10.45 kcal $/ \mathrm{mol})$ (Fig. 13) and the compound $\mathrm{CN}-02$ had the binding affinity $(\Delta \mathrm{G}$, Binding energy $=-10.50 \mathrm{kcal} / \mathrm{mol}$ ).

This discussion showed that the compounds (CN-02) had a high binding affinity $(\Delta \mathrm{G}$, Binding energy $=-10.50 \mathrm{kcal} / \mathrm{mol})$ showing three hydrogen bonding with protein VAL650, THR 676, LYS 680, three intense hydrophobic interactions were showed with protein TYR 90, TYR648, TYR648 (Fig. 14), salt bridge interaction was also there with protein LYS680 along with one pi-stacking interaction with protein TYR 90 (Fig. 15).

\section{CONCLUSION}

The receptor (protein) and ligand play an important role in structural based drug design. In the present work, phytochemicals were obtained from the whole plant of $C$. cretica by column chromatography. The presence of different bioactive compounds provides evidence for the efficacious use of plant parts for various ailments by traditional specialists. In this investigation, we docked the receptor (glycogen phosphorylase protein) holds a promising lead target formation against diabetes based on molecular docking analysis (minimum hydrogen bond length and maximum docked score). Thus, these compounds can be effectively used as drugs for treating diabetes which is predicted on the basis of docking scores.

\section{AUTHORS' CONTRIBUTIONS}

Sangeeta Rani contributed to the preparation Manuscript, Dr. Kavita Gahlot contributed to the data interpretation and finalization of the manuscript, and Dr. Arvind Kumar supervised and reviewed the manuscript.

\section{CONFLICTS OF INTEREST}

None.

\section{AUTHORS' FUNDING}

Nil.

\section{REFERENCES}

1. Hanrahan JE, Subroto PA, Priawan RP, Krisnamurti DG. Potential holistic preventive and therapeutic effects of Garcinia mangostana extract or isolates in Type 2 diabetes mellitus: A review. Int J Appl Pharm 2019;11:7-11.

2. Sudhanshu KB, Supriya K, Ashwini K, Awanish K. Antidiabetic phytoconstituents and their mode of action on metabolic pathways. Ther Adv Endocrinol Metab 2018;9:81-100.

3. World Health Organization. Diagnosis and Classification of Diabetes Mellitus and its Complications. Report of a WHO Consultation. Geneva: World Health Organization; 1999. p. 2.

4. Bruno MM, Ama M, Cacral P, Biapa N, Pauline N, Francine TN, et al. Antioxidant and synergistic antidiabetic activities of a three-plant preparation used in Cameroon folk medicine. Int Sch Res Notices 2017;2017:9501675.

5. Umar A, Ahmed QU, Muhammad BY, Dogarai BB, Soad SZ. Antihyperglycemic activity of the leaves of Tetracera scandens Linn. Merr. (Dilleniaceae) in alloxan induced diabetic rats. J Ethnopharmacol 2010;131:140-5

6. Paarakh MP. In silico antidiabetic activity of limonene isolated from Coriandrum sativum Linn fruit. Acta Sci Pharm Sci 2018;2:2-6.

7. Menaka CT, Ravirajsinh NJ, Ansarullah T, Ranjitsinh VD, Ramachnadran AV. Prevention of high fat diet induced insulin resistance in C57BL/6J mice by Sida rhomboidea ROXB. Extract. J Health Sci 2010;56:92-8

8. Amos AF, Carty MC, Zimmet P. The rising global burden of diabetes and its complications: Estimates and projections to the year 2010. Diabet Med 1997; 14:S5-85.

9. Bibi N, Wara B, Mughal S, Morrissey H, Ball P. A critical literature review and audit of real world data to inform the relationship between mental Ill-health and Type-2 diabetes favourable prognosis. Int J Pharm Pharm Sci 2020;12:43-47.

10. Sunil C, Latha PG, Suja SR, Shine VJ, Shyamal S, Anuja GI. Effect of ethanolic extract of Pisonia alba Span. Leaves on blood glucose levels and histological changes in tissues of alloxan induced diabetic rats. Int J Appl Res Nat Prod 2009;2:4-11.

11. Kyriacou A, Ahmed AB. Exenatide use in the management of Type 2 diabetes mellitus. Pharmaceuticals 2010;3:2554-67.

12. Pandita R, Phadke A, Jagtap A. Antidiabetic effect of Ficus religiosa extract in streptozotocin-induced diabetic rats. J Ethnopharmacol 2010;128:462-6

13. Abdallah HM, Elshamy IA, Gaber El, Gawad AM, Omer EA, Leo, MD, et al. Anti-inflammatory, antipyretic, and antinociceptive effects of a Cressa cretica aqueous extract. Planta Med 2017;83:1313-20.

14. Taha SE, Nagwa MA, Sahar YA, Salama M, Hanan F, Asmaa A. Cressa cretica L. Growing in Egypt: Phytochemical study and potential antioxidant and hepato-protective activities. J Appl Pharm Sci 2019;9:46-50.

15. Babu EN, Anusha N, Rani P. Phytochemical screening and in vivo antiulcer activity of methonolic extract of Cressa cretica (Linn). World J Pharm Pharm Sci 2018;7:621-8.

16. Afshari A, Sayyed-Alangi SZ. Antioxidant effect of leaf extracts from Cressa cretica against oxidation process in soybean oil. Food Sci Nutr 2017:5:324-33.

17. Shahat AA, Nazif NM, Nahla AA, Pieters S, Vlietinck AJ. Flavonoids from Cressa cretica. Qatar Univ Sci J 2005;25:72-7.

18. Rajan ST, Aanandhi VM. Molecular docking studies of isolated flavonoids compounds from Amaranthus tristis Linn. As alpha-amylase and alpha-glucosidase activators. Asian J Pharm Clin Res 2018;11:62-5. 
19. Government of India, Ministry of Health and Family Welfare. The Ayurvedic Pharmacopoeia of India. $1^{\text {st }}$ ed., Vol. 3, Part. 1. New Delhi: Ministry of Health and Family Welfare; 2001. p. 233-25.

20. Raman N. Phytochemical Composition, Mosquito Larvicidal. New Delhi: New India Publishing; 2006. p. 19-24.

21. Agarwal SS, Paridhavi M. Herbal Drug Technology. Hyderabad: University Press India Pvt. Ltd.; 2007.

22. Lamia A, Habiba L, Amel A, Francisco L, Ignacio B, Samir B, et al. Isolation, antioxidant and antimicrobial activities of ecdysteroids from Serratula cichoracea. Curr Bioact Compd 2018;14:60-6.

23. Raeisi S. Molecular docking studies of squalene synthase inhibitors as potential anti cardiovascular disease drugs: Insights into drug-protein interaction discovery. Pharm Sci 2013;19:39-44.

24. Pence HE, Williams A. Chem spider: An online chemical information resource. J Chem Educ 2010;87:1123-4.

25. Mohd Q, Jamal S, Gupta R, Siddiqui MH, Kesari KK, Wadhwa G, et al. Titanium dioxide nanoparticles provide protection against polycyclic aromatic hydrocarbon $\mathrm{BaP}$ and chrysene-induced perturbation of DNA repair machinery: A computational biology approach. Biotechnol Appl Biochem 2016;63:497-513.

26. Johnson LN, Barford D. A minireview on glycogen phosphorylase. J Biol Chem 1990;265:2409.

27. Ortmeyer HK, Bodkin NL, Hansen BC. Nature London. Am J Physiol 1989;340:E133. 